\title{
Smart monitoring system for risk management in the underground space
}

\author{
Isam Shahrour 1, 2, Hanbing Bian ${ }^{1,2}$, Xiongyao Xie ${ }^{2}$, Zixin Zhang ${ }^{2}$ \\ 1 Department of Geotechnical Engineering, School of Civil Engineering, Tongji University, \\ Shanghai 200092, China \\ 2 Laboratoire de Génie Civil et géo-Environnement, Université de Lille, F-59000 Lille, \\ France
}

\begin{abstract}
This paper presents a smart monitoring system for risk management in the underground space. This space has a major role in cities, but it suffers from high vulnerability to hazards such as fire, flood and accidents. The paper provides analysis of the vulnerability of the underground space and shows how a smart monitoring system of human presence, indoor conditions, underground space access and equipment performances with advanced data analysis could help in improving the risk management in this space.
\end{abstract}

\section{Risk in the underground space}

\subsection{Role of the underground space in urban area}

The high urbanization requires an increasing use of the underground space, which become crucial for urban development. This space is used in urban transportation for underground roads, subways and logistic facilities. It hosts urban utilities such as water, energy and communications. It is also used for the construction of buildings and facilities for residential, industrial and services purpose. In some cities, this space covers large areas and constitutes real districts.

\subsection{Vulnerability of the underground space}

The underground space suffers from vulnerability to urban hazards such as fire, flood and accidents. Safety constitutes the great challenge of this space. Indeed, an incident in the underground space could be catastrophic and lead to huge economic and social damages. Safety in the underground space is more critical than that in the ground surface, because of access restriction. Accidents could concern structural instability, water infiltration, fire, electrical outage and air contamination, etc. An incident such as flood or fire could lead very quickly to serious damages of underground system equipment.

The International Tunneling Association published guidelines for tunneling risk management in 2004 (Eskesen et al., 2004). According to these guidelines, risk management should be included in the planning and construction of any major underground 
project. In China, the first guideline for risk management in tunnels and underground works was published in 2007, and then it was updated as a national code for urban rail transit in 2012. Hu and Huang (2014) indicated that risk in large underground projects in China was generally managed through engineering decision, which resulted in shortcomings concerning the use of an integrated risk management approach.

The key point of the implementation of risk management in underground space concerns the identification of sources of potential risk, elaboration of corresponding preventive measures and preparing emergency rescue plan. Dynamic risk management should be established on an information-based construction and site monitoring ( $\mathrm{Hu}$ and Huang, 2014).

\subsection{Fire hazard}

Fire is one of the most serious disaster in the underground space. Almost one-third of accidents in the urban underground space are associated with fire hazard. In 1999, China suffered from 4059 fire accidents in the urban underground space, which caused around 340 deaths. While in the same time, China suffered of 1122 fires with bout 66 deaths in fires in high-rise buildings (Yao et al., 2012). Obviously, fire accidents are more serious in the urban underground space than those in high-rise buildings. Indeed, the underground space is a narrow space with limited access, poor natural ventilation and restricted natural light.

Fire in the urban underground space has specific features. It consumes oxygen, which is also essential for human being. During fire in the urban underground space, air refreshing is ensured by the ventilation system, which is also vulnerable to fire. In addition, fire generates high quantity of toxic smoke. Trapped persons suffer not only from oxygen shortage and toxic smoke, but also from reduced visibility, which causes difficulties in the evacuation and emergency operations.

Firefighting in the underground space is more complicated than in the surface. Researches conducted after the fire at King's Cross of London Underground in 1987 (Moodie, 1992), showed the "trench effect": fire has high capacity in propagation in the narrow underground ground space. Moreover, the fire cannot be detected easily in the underground space. Firefighters should access to the underground via spaces, which are already occupied by users, smoke hot air flux and evacuations.

In order to prevent fire propagation in the underground space, this space must be strictly divided into fire prevention zones. Each zone should have independent ventilation system. In case of fire incident, communications between fire zones could be closed rapidly. According to the Chinese national norms, the fire zone in urban underground space is limited to $500 \mathrm{~m}^{2}$. This limit could be extended to $2000 \mathrm{~m}^{2}$ by the installation of specific fire preventions equipment.

According to regulations, fire protection facilities such as emergency lighting system, emergency evacuation indication sign, automatic fire and smoke alarm, system and emergency broadcast system should be configured to ensure normal use during fire incident. Important facilities are encouraged to use innovative technology for firefighting. For example, after two serious fire accidents, the Channel Tunnel was equipped with automatic temperature detection system for fire early detection.

\subsection{Flood hazard}

Flood in the underground space could lead very quickly to dramatic catastrophe, because of the limited space, the high gravity water flow and access restriction. The rapid increase in the water level could lead to electrical outage, which could stop water pumps and 
consequently accelerate water level rising. In addition, high human concentrations in the subway or in underground commercial centres could be surprised by the sudden increase in the water level and limited evacuation possibilities (Kyoko et al. 2016). In some cities, since the underground passages and buildings are connected, water can easily flow to large underground areas.

The dramatic impacts of flood on the subways of New York and Taiwan provide a clear picture about the destructor effect of flood in the underground space. The superstorm Sandy in 2012 caused the flood of several stations in New York City subway. The subway was shut down for days. The flood resulted in about $\$ 5$ billion in damage to the transport system. The Typhoon Nari in 2001 caused failure to several pumping stations in the subway of Taiwan and flood of some stations. It caused 94 deaths and approximately $\$ 800$ million of damage.

Two strategies are combined for flood risk of mitigating in the underground space: structural and non-structural. The former includes engineered solutions to reduce impact of flooding, such as building barriers, dams, large storm water facilities, flood gates and raised entrances at underground stations. The second concerns reduction of both flood risks and impact through policies, laws, public awareness and education. It includes also preventing loss of permeable surfaces, and early warning systems. In the underground space, managers can install backup power for pumps to reduce fault risk due to electrical outage.

However, flood risk continues to be a serious hazard for the underground space in some cities. The use of the smart technology will help in reducing the impact of this risk.

\section{Smart technology}

\subsection{Smart Solution}

The smart technology could be used to establish an integrated solution for the risk management of the underground space. Figure 1 shows the architecture of this solution. It includes 4 layers:

- Digital model: This layer includes data concerning the underground space architecture and equipment as well as their attributes. BIM constitutes a powerful tool for the construction of this layer; it offers a friendly graphic environment and data processing capacity for collaborative design and management of complex projects. The digital model includes digital identification and geo-localization of the components of the tunnel and its equipment. Each component is equipped by RFID tags (RadioFrequency Identification), which provide dynamic information about the component including manuals, guides, photos and videos.

- Monitoring system: This layer includes the monitoring system which is used for the security of the underground space; sensors and cameras are used to track indoor conditions, tunnel access status, ventilation system and pumps functioning, smoke extractors, emergency exist indications, water level.

- Data analysis: This layer includes engineering, safety and advanced Information Technology tools such as the Artificial Intelligence. It allows to detect early faults and to take actions to stop their extension, to protect people and material, to operate recovery actions and to realize post-fault analysis to learn from the incident to improve the underground resiliency.

- Control system: This layer includes electronic devices such as motors, breakers, switches, valves and pumps which could be commanded by machines or by technical staff. 


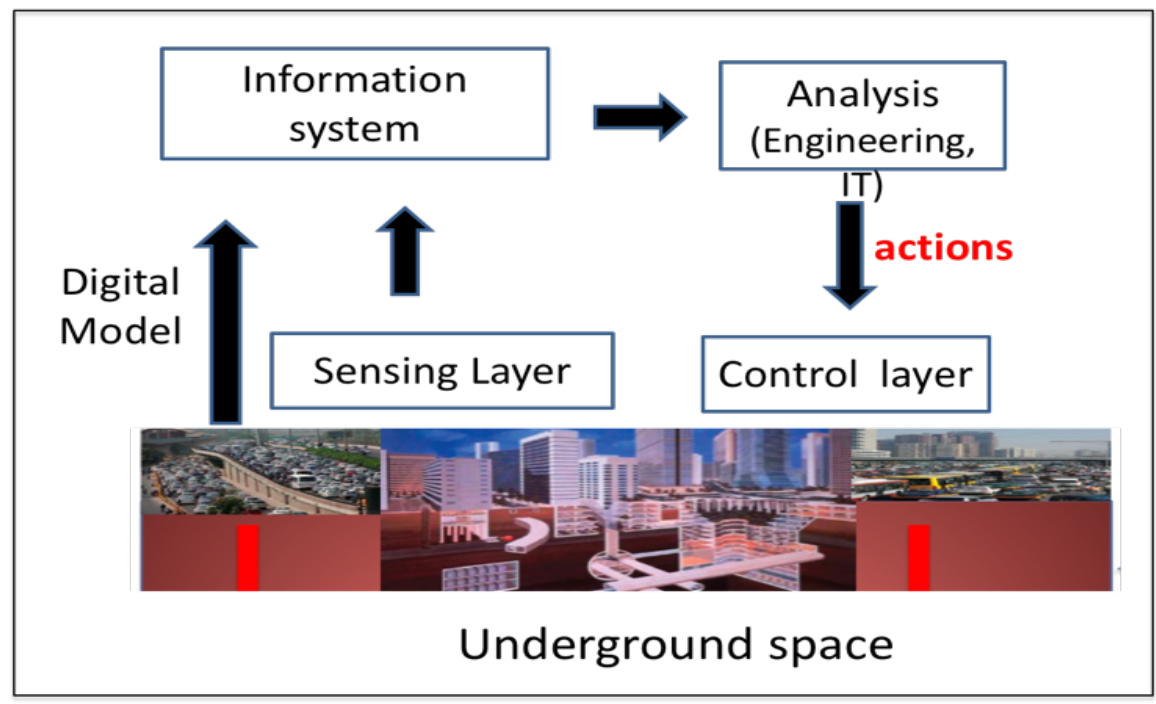

Figure 1: Architecture of the smart solution for the underground space

\subsection{Smart monitoring of the underground space}

The underground space is organized in security areas, which could be public areas or restricted-access areas (technical areas). Each security area is equipped by a monitoring system to track (i) human presence, (ii) indoor conditions, (iii) access control and (iv) equipment performances (Figure2).

\section{Human presence:}

The underground space includes generally public and restricted areas. For security management, it is of major concern to know at each instant the human presence in these areas.

For public areas, cameras are used to track the human presence. Image processing tools allow to have a good estimation of the density of human presence, which is necessary for emergency actions.

For restricted-access area, specific digital identification systems could be used for the human presence control. Each authorized employee is identified through a digital ID, which provides information about the employee's identity, contact, hierarchy and authorized area. Presence in the tunnel is tracked using internal geo-localization system (Khoury and Kamat, 2009; Lin et al. 2013). At each instant, the system provides the identity and location of employees in the underground space.

\section{Indoor conditions}

Sensors are installed in each area of the underground space to track the indoor security parameters such as temperature, humidity, air quality, smoke concentration, gas concentration and water infiltration.

\section{Access control}

The underground space accesses are equipped by electronic devices that indicate the status of the access (open/close) and enables the access control.

\section{Equipment performances control}


Devices concerned by the underground space security (access control, ventilation, smoke extraction, firefighting, water pumping, emergency lighting...) are equipped by electronic systems that can control regularly the devices performances and indicate to staffs' any anomaly in the security equipment and their consequences.

\section{D graphic system interface}

A 3D graphic interface is used for a real time visualization of the security condition in the underground space. For each security area, it indicates in 3D graphic environment for each security indicator (human presence, indoor condition, access control, equipment performances) the current value and security operating interval (min, max); in case of violation of security conditions, the graphic system indicates the location, severity, impact and actions to be taken.

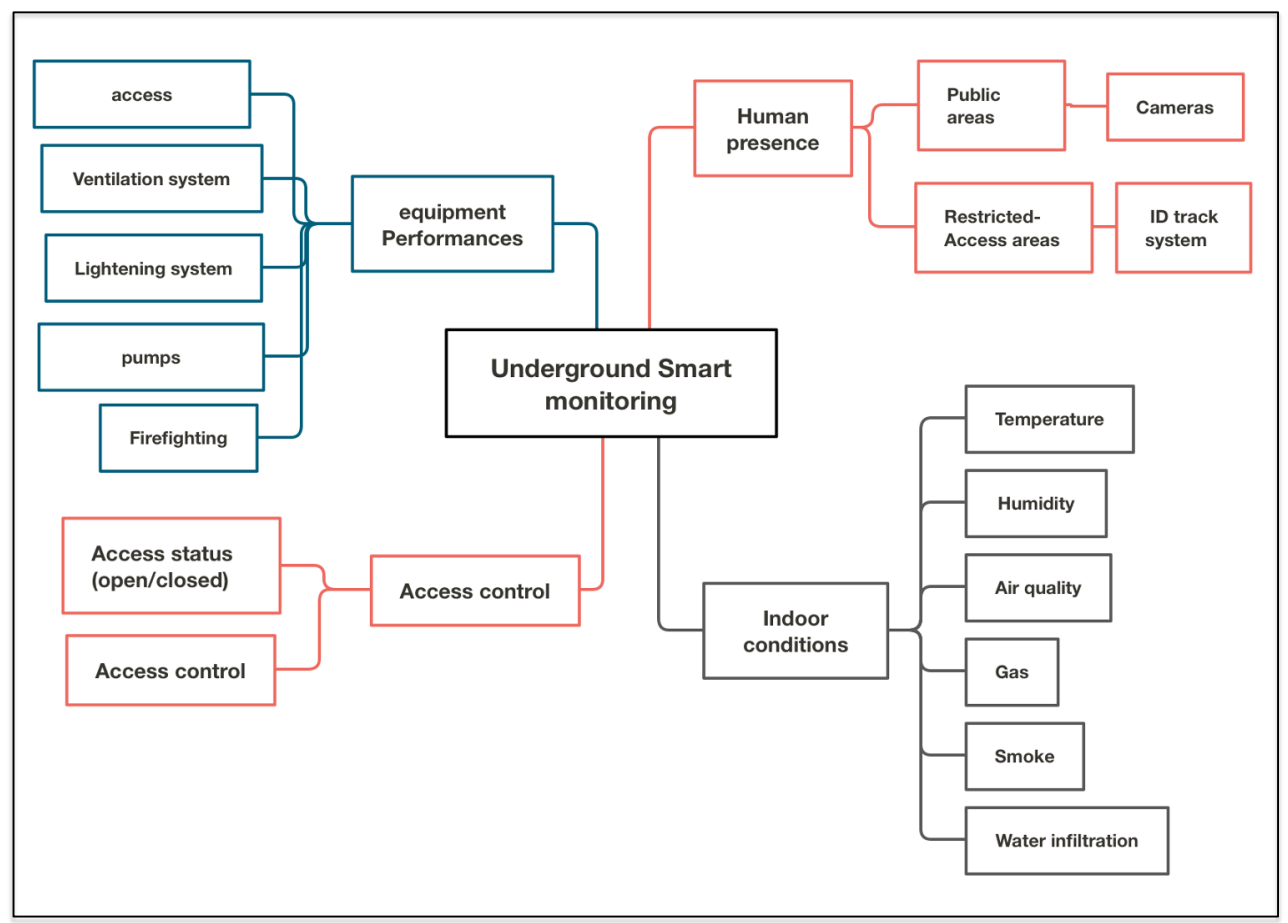

Figure 2: Smart monitoring system for the risk management of the underground space

\section{Conclusions}

The underground space is largely used in urban development, in particular for transportation, water and energy supply and commercial activity. This use is subjected to serious urban hazards such as fire and flood, which could lead to dramatic catastrophes. In order to improve the risk management of this space, this paper presented an integrated solution that uses the smart technology to monitor human presence, indoor conditions, underground space access and equipment performances. Thanks to advanced analysis tools and $3 \mathrm{D}$ graphic interface, this system provides for each security indicator the current value as well as the accepted operating interval; in case of violation of security conditions, the system indicates the location, severity, impact and actions to be taken. 


\section{References}

1. Eskesen S.D., Tengborg P., Kampmann J. and Veicherts T.H., 2004. Guidelines for tunnelling risk management: International Tunnelling Association, Working Group No. 2. Tunnelling and Underground Space Technology, Vol.19, 217-237.

2. Hu Q., Huang H., (2014) The State of the Art of Risk Management Standards on Tunnels and Underground Works in China. 2nd International Conference on Vulnerability and Risk Analysis and Management (ICVRAM), Liverpool, UK.

3. Khoury H.M., Kamat V.R., 2009. Evaluation of position tracking technologies for user localization in indoor construction environments. Automation in Construction, Vol.18 (4), 444-57.

4. Kyoko Niira, Katsutoshi Shigeno, Masahiko Kikucha, Tadashi Inoue, (2016) Disasterprevention measures for underground space to deal with large-scale earthquakes and intensified flood disasters in Japan, 15th International scientific conference "Underground Urbanisation as a Prerequisite for Sustainable Development", Procedia Engineering 165 ( 2016 ) $224-232$.

5. Lin P., Li Q.B., Fan Q.X., Gao X.Y., 2013. Real-time monitoring system for workers' behavior analysis on a large-dam construction site. International Journal of Distributed Sensor Networks, 2013, http://dx.doi.org.gate6.inist.fr/10.1155/2013/509423.

6. Moodie, K. The King's Cross Fire: Damage Assessment and Overview of the Technical Investigation, Fire Safety Journal, vol 18 (1992) 13-3.

7. Yao Y., Zhang J., Tao J., et al., Safety problems in crowded underground space in Beijing, Procedia Engineering 45 (2012) 763 - 767. 